6 hours in that of the $\beta$-naphthyl derivative. The addition of aniline or quinoline to the alcoholic solution of the phenylamidic acid and of $\beta$-naphthylamine to that of the $\beta$-naphthylamidic acid produced no effect. It is clear, therefore, that these two acids resemble the aliphatic amidic acids and differ from those of the aromatic series.

\title{
Summary.
}

I. We have prepared a number of phthalamidic acids of the type $\mathrm{RNHCOC}_{6} \mathrm{XCO}_{2} \mathrm{H}$, where $\mathrm{R}=$ phenyl or $\beta$-naphthyl and $\mathrm{X}$ represents $\mathrm{H}_{2} \mathrm{Cl}_{2}, \mathrm{Cl}_{4}$ or $\mathrm{H}_{3} \mathrm{NO}_{2}$.

2. The behavior of these acids when heated with alcohol alone and also with alcohol and amines has been studied.

3. The accumulation and approximation of negative groups in the phthalic acid nucleus favors the formation of diamides, $\mathrm{C}_{8} \mathrm{X}(\mathrm{CONHR})_{2}$, rather than that of imides, $\mathrm{C}_{6} \mathrm{X}<\mathrm{CO}>\mathrm{NR}$.

4. Camphoramidic acids, $\mathrm{RNHCOC}_{8} \mathrm{H}_{14} \mathrm{CO}_{2} \mathrm{H},\left(\mathrm{R}=\mathrm{C}_{6} \mathrm{H}_{5}\right.$ or $\beta$-naphthyl $)$ resemble the corresponding aliphatic acids and not those of the aromatic series. They are stable under the conditions employed.

5. A number of new compounds are described, and improved methods have been worked out for the preparation and purification of certain substances which had been obtained previously by other chemists.

The investigation is being continued in various directions.

MCMASTER UNIVERSITY.

TORONTO, CANADA.

\section{THE BASIC PROPERTIES OF OXYGEN: COMPOUNDS WITH BRO- MINE AND IODINE.}

BY D. MCINTOSH.

Received August 5, 1910.

Two addition compounds of ether and bromine are known. One, which we may call the tribromide (m. p. $\left.22^{\circ}\right)^{1}$ consists of three, and the other, the dibromide (m. p. $\left.-40^{\circ}\right)^{2}$, of two atoms of bromine to a molecule of ether.

The constitution of the dibromide may be explained in several ways, assuming the oxygen to be quadrivalent and the bromine uni- or trivalent. The tribromide, however, can be conveniently expressed only by doubling the formula and writing it $\mathrm{C}_{4} \mathrm{H}_{10} \mathrm{O}=\mathrm{Br}-\mathrm{Br}=\mathrm{Br}-$ $\mathrm{Br}=\mathrm{Br}-\mathrm{Br}=\mathrm{OH}_{10} \mathrm{C}_{4}$; and as nothing is known against this mode of representing the dibromide, either in regard to its molecular weight or its reactions, its formula, too, may be doubled, $\left(\mathrm{C}_{4} \mathrm{H}_{10} \mathrm{O}=\mathrm{Br}-\right.$ $\mathrm{Br}=\mathrm{Br}-\mathrm{Br}=\mathrm{OH}_{10} \mathrm{C}_{4}$ ).

${ }^{1}$ Schützenberger, Ann., 167, 86 (1873).

2 Trans. Chem. Soc. (London) 87.784 (1905). 
In a recent paper Chelintzev and Kepovalov ${ }^{1}$ criticize these formulas and attempt to show that the dibromide has the constitution $\mathrm{C}_{4} \mathrm{H}_{10} \mathrm{O}<{ }_{\mathrm{Br}}^{\mathrm{Br}}$. As I have tried to determine the molecular weights of these and similar compounds, a brief account of the work may be useful; and while it has been found impossible to decide on the correct formulas it can at least be shown that Chelintzev and Kepovalov misinterpret the results of their experiments.

These investigators prepare what they believe to be the dibromide ether complex by adding absolute ether to pure bromine. After the reaction is complete, the excess of ether is removed by heating to $30^{\circ}$ under reduced pressure. They obtain an oily orange-red liquid, etc.

Under such conditions the dibromide is not formed but a mixture of substitution products colored by bromine is produced as repeated analyses have shown. The dibromide can be prepared only with the greatest care at a low temperature. Then it may be obtained with less than $1 / 20$ per cent. hydrobromic acid. Above its melting point $\left(-40^{\circ}\right)$ substitution takes place, so that a mixture of bromine and ether may contain a large amount of acid.

In parallel columns are placed the properties given to the compound by Chelintzev and his collaborator and those of the pure dibromide.

\section{Chelintzev and \\ Kepovalov.}

Orange-red liquid.

Soluble in benzine, benzene and carbon disulphide on warming, precipitated on cooling.

Soluble in chloroform.

Partly soluble in carbon tetrachloride.

Soluble in ethyl alcohol and ethyl acetate with heat evolution.

Changed slowly by $\mathrm{KOH}$ solution.

Acid fumes evolved in strong sulphuric acid.

Little affected by sodium acid sulphite solution.

Slowly acts on potassium iodide solution.

Heat of formation 9130 cal.

\section{MeIntosh.}

Bromine colored liquid.

Decomposed.

Largely decomposed.

" $"$ "

Instantly decomposed.

Instant decomposition with liberation of iodine

Under 2000 cal

These investigators find the molecular weight of their compound in acetic acid by the cryoscopic method to be about 240 . The dibromide, however, is decomposed by this solvent and its molecular weight cannot be determined.

Freezing-point measurements of this substance were made with chloroform (m. p. $-63^{\circ}$ ) as solvent. The compound was partly decomposed, 1 Ber., 42, 153I (1909). 
and the freezing-point lowerings, although a little less than the sum of the ether and bromine depressions determined separately, could not be used to fix its molecular weight.

An attempt was made to determine the molecular weight of these bromides by Ramsay and Shields' method. The figures for the tribromide ${ }^{1}$ may be given:

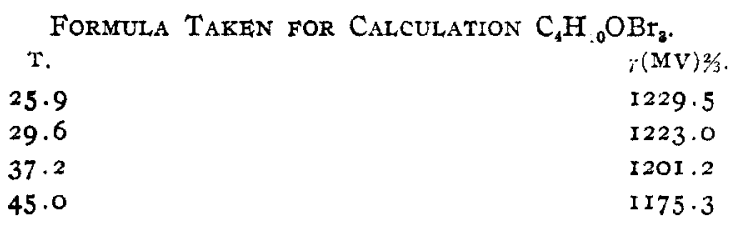

When plotted these members lie approximately in a straight line. Between $25^{\circ}$ and $45^{\circ} \frac{d r(\mathrm{MV})^{2} / 3}{d \mathrm{~T}}=2.85$ while for normal compounds the value is 2.I2. Clearly the compound is largely dissociated. The dibromide separates into two layers $10^{\circ}$ above its melting point. It, too, is largely dissociated.

These results show that the ordinary methods of molecular weight determinations are not applicable to these oxonium compounds, and that the formulas must remain in doubt until other methods are devised.

While examining the action of bromine and chlorine on the alcohols, ketones, etc., in 1905, a large amount of time was spent in attempting to produce analogous compounds with iodine. Quite recently Waentig ${ }^{2}$ has made some experiments on this point and believes that he has obtained addition products at low temperatures.

When a solution of iodine in alcohol or acetone is cooled to $-80^{\circ}$ or $-90^{\circ}$ the iodine may separate and be mistaken for a compound, but when carefully dried at a low temperature analyses show the product to be iodine contaminated with a little of the organic solvent. With ethyl acetate mixed crystals of the solvent and iodine may be obtained.

Bromine and chlorine when dissolved in organic substances containing oxygen give a noticeable heat evolution; iodine a slight heat absorption.

If iodine gives compounds analogous to those formed by the other halogens, the reaction between iodine and ether may be represented by the equation

$$
\mathrm{C}_{4} \mathrm{H}_{10} \mathrm{O}+\mathrm{I}_{2} \leftrightarrows \mathrm{C}_{4} \mathrm{H}_{10}^{\mathrm{B}} \mathrm{OI}_{2}
$$

or $K=B / A$, where $K$ is the equilibrium constant, and $B$ and $A$ the

${ }_{1}$ The tribromide always contains several per cent. hydrobromic acid.

'Z. physik. Chem., 68, 1513 (1909). 
concentrations of the substances involved.

From van't Hoff's equation

$$
\log \mathrm{K}_{2}-\log \mathrm{K}_{1}=\frac{q}{2}\left(\frac{\mathrm{I}}{\mathrm{T}_{1}}-\frac{\mathrm{I}}{\mathrm{T}_{2}}\right)
$$

Where $K_{1}$ and $K_{2}$ are the equilibrium constants at the temperatures $T_{1}$ and $T_{2}, T_{2}$ being the higher, and $q$ the heat of formation of $A$. Since $q$ is positive ${ }^{1} \mathrm{~K}_{2}$ must be larger than $\mathrm{K}_{1}$ or less of the compound is produced at a low temperature than at a higher one. It seems probable, then, that these compounds cannot be produced in a reasonably pure state by cooling their solutions to a low temperature.

MCGILL UNIVERSITY.

[CONTRIBUtion FROM THE CHEMICAL LABORATORY, UNIVERSITY OF ILLINOIS.]

\section{MOLECULAR REARRANGEMENTS OF CARBON COMPOUNDS. ${ }^{2}$}

BY C. G. Derick.

Received July 12, 1910.

Table of Contents.

I. Types of Chemical Reaction. 2. Formation and Stability of Compounds that Rearrange. 3. Catalysis of Speed of True Rearrangements of the Non-reversible Type. 4. A Correlation of True Molecular Rearrangements of Acids and Bases, Belonging to the Non-reversible Type, with the Free Energy of Ionization. 5. Rearrangements of Unsaturated Acids. 6. Illustrations of True Rearrangements of Nonreversible Type. 7. Rearrangements with Reaction. 8. Review of the Field of Molecular Rearrangements.

\section{Types of Chemical Reaction.}

In the study of molecular rearrangements of carbon compounds, two types of chemical reactions are noted; the reversible and non-reversible. ${ }^{3}$ Tautomerism furnishes many examples of molecular rearrangements of the reversible type. Wislicenus showed, in the case of formylphenylacetic ester, ${ }^{4}$ that in certain solvents an equilibrium between the two isomeric forms is established, which equilibrium is dependent upon temperature, concentration, and the nature of the solvent. Molecular rearrangements of the non-reversible type are illustrated by the change of $\Delta^{2}$ unsaturated acids into their $\Delta^{1}$ isomers by boiling with alkalis.

A further study of reversible and non-reversible molecular rearrangements shows that certain rearrangements occur when atoms are added to or substracted from the original molecule, while in many other cases the rearrangement consists only in the readjustment of the atoms already present in the molecule. Molecular rearrangements of the former class

1 Contrast Hildebrand and Glascock, Thrs JournaI, 3I, 26 (Igog).

2 Presented in abstract at the Boston meeting of the American Chemical Society. From the author's thesis in partial fulilment of the requirements for the degree of Doctor of Philosophy at the University of Illinois.

'For a definition of these terms see Nernst, Theoretische Chemie, Sechste Auflage, especially pages $668-70$.

- Wislicenus, Ann., 306, 322 (1899); 300, 206. 